\title{
MATLAB Based Modelling and Performance Study of Series Connected SPVA under Partial Shaded Conditions
}

\author{
Ramaprabha Ramabadran (Corresponding author) \\ Department of EEE, SSN College of Engineering \\ Rajiv Gandhi Salai, Chennai -603 110, Tamilnadu, India \\ Tel: 91-44-2727-5064 E-mail: ramaprabhasuresh@gmail.com \\ Badrilal Mathur \\ Department of EEE, SSN College of Engineering \\ Rajiv Gandhi Salai, Chennai- 603 110, Tamilnadu, India \\ Tel: 91-44-2727-5064Ｅ-mail: blmathur@ssn.edu.in
}

\begin{abstract}
In a solar photovoltaic array (SPVA) spread over vast area, it is likely that shadow may fall over some of its cells due to tree leaves falling over it, birds or bird litters on the array, shade of a neighboring construction, passing clouds etc. Under partial shaded conditions the PV characteristics get more complex with multiple peaks. It is important to understand and predict them to get maximum possible power from the SPVA. This paper presents a MATLAB-based modelling and simulation scheme suitable for studying the characteristics of a series connected SPVA under partial shaded conditions. The conventional model is modified to include the effect of shading in the SPV module parameters for simulation study. The simulation of MPPT algorithm to track the global maximum is also presented. The model is practically validated using electronic load.
\end{abstract}

Keywords: Solar PV array, Partial shading, Improved model, Electronic load, Matlab

\section{Nomenclature}

$\begin{array}{ll}\mathrm{I}_{\mathrm{PV}}, \mathrm{V}_{\mathrm{PV}} & - \text { Solar PV module Current }(\mathrm{A}) \text { and Voltage }(\mathrm{V}) \text { respectively } \\ \mathrm{I}_{\mathrm{ph}} & - \text { Photo current SPV module }(\mathrm{A}) \\ \mathrm{I}_{\mathrm{r}} & - \text { Diode reverse saturation current in the equivalent circuit }(\mu \mathrm{A}) \\ \mathrm{R}_{\mathrm{se}} & - \text { Series resistance in the equivalent circuit of the module }(\mathrm{m} \Omega) \\ \mathrm{R}_{\mathrm{sh}} & - \text { Parallel resistance in the equivalent circuit of the module }(\Omega) \\ \mathrm{R}_{\mathrm{L}} & - \text { Load resistance } \\ \mathrm{D} & - \text { Diode used in the equivalent circuit } \\ \mathrm{n} & - \text { Diode ideality factor }(1<n<2 \text { for a single solar cell) } \\ \mathrm{q} & - \text { Electron charge }(=1.602 \times 10-19 \mathrm{C}) \\ \mathrm{k} & - \text { Boltzman's constant }(=1.381 \times 10-23 \mathrm{~J} / \mathrm{K}) \\ \mathrm{T} & - \text { Temperature (Kelvin) } \\ \mathrm{V}_{\mathrm{t}} & - \text { Thermal voltage }(=\mathrm{nkT} / \mathrm{q}) \\ \mathrm{G} & \left.- \text { Insolation level (at reference condition } \mathrm{G}=1000 \mathrm{w} / \mathrm{m}^{2}\right) \\ \alpha & - \text { Short circuit current temperature co-efficient } \\ \mathrm{I}_{\mathrm{sc}} \& \mathrm{~V}_{\mathrm{oc}} & - \text { Short circuit current and open circuit voltage of the module respectively } \\ \mathrm{V}_{\mathrm{mp}} \& \mathrm{I}_{\mathrm{mp}} & - \text { Maximum power point voltage and current respectively } \\ \mathrm{PV} \mathrm{V}_{\mathrm{max}} & - \text { Maximum power } \\ \mathrm{D}_{\mathrm{b}} & - \text { Bypass diodes used in the series array configuration } \\ \mathrm{ref} & - \text { Additions subscripts indicate the parameters at reference conditions } \\ & \end{array}$


1,2,3 Additional subscripts indicate the parameters of Panel-1, Panel-2 \& Panel-3

respectively

$\mathrm{V}_{11}, \mathrm{~V}_{12}, \mathrm{~V}_{13}$ - Operating points of Panel-1 in series connection

$\mathrm{V}_{21}, \mathrm{~V}_{22}, \mathrm{~V}_{23}$ - Operating points of Panel-2 in series connection

$\mathrm{V}_{31}, \mathrm{~V}_{32}, \mathrm{~V}_{33}$ - Operating points of Panel-3 in series connection

$\mathrm{I}_{1}, \mathrm{I}_{2}, \mathrm{I}_{3} \quad$ - Operating point currents of series connected SPVA

$\mathrm{P}_{1}, \mathrm{P}_{2}, \mathrm{P}_{3} \quad$ - Power at operating points

\section{Introduction}

Global warming and increasing prizes of fossil fuels have drawn more attention towards the usage of renewable energy sources particularly solar energy because of its well known advantages. A great deal of research has been conducted in this field over the last few decades. Solar PV panel is a power source having non linear internal resistance. A major challenge in using a SPV source containing a number of cells in series is to deal with its non-linear internal resistance. The problem gets all the more complex when the array receives non-uniform insolation. Cells under shade absorb a large amount of electric power generated by cells receiving high insolation and convert it into heat. This heat may damage the low illuminated cells under certain conditions. To relieve the stress on shaded cells, bypass diodes are added across the modules. In such a case multiple peaks in power-voltage characteristics are observed under non uniform illumination. Classical Maximum Power Point Tracking (MPPT) methods are not effective due to their inability to discriminate between local and global maxima (Eftichios Koutroulis et al, 2001; K. H. Hussein et al, 1995; S. Jain and V.Agarwal, 2004). Nevertheless, it is very important to understand the characteristics of SPV under partial shaded conditions to use PV installations effectively under all conditions. Analog models of SPV sources at varying temperature, insolation and partial shaded conditions were presented in the literature (G.Walker, 2001). This paper presents the improved model of SPVA which takes care about the dependence of all the parameters in the model with respect to insolation and temperature (Gow.J.A. and Manning.C.D., 1996; H. Kawamura et al, 2003; M. C. Alonso-Gracia et al, 2006; Karatepe et al, 2006; Ramaprabha and B.L.Mathur, 2009). The model was simulated using Matlab software. The developed model was validated with experimental results. To capture the characteristics under constant insolation and temperature conditions, the experimental characteristics were obtained using linear MOSFET as an electronic load (Yingying Kuai and S. Yuvarajan, 2006; Ramaprabha and B.L.Mathur, 2008).

\section{Improved Model of SPVA under Partial Shaded Conditions}

The equivalent circuit model of a solar cell consists of a current generator and a diode plus series and parallel resistance as shown in Figure 1. The mathematical equation expressing the output current of single cell is given by equation (1)

$$
I_{P V}=I_{p h}-I_{r}\left[\exp \left\{\frac{V_{P V}+I_{P V} R_{s e}}{V_{t}}\right\}-1\right]-\frac{\left(V_{P V}+I_{P V} R_{s e}\right)}{R_{s h}}
$$

To get the improved model, the effect of insolation and temperature on each parameter has to be evaluated. For this, the following five reference parameters are required. They are $V_{\text {tref, }} I_{\text {rref }}, I_{\text {phref }}, R_{\text {seref }}$, and $R_{\text {shref }}$ are required. To find the reference parameters it is important to know the following parameters. (Ramaprabha and B.L.Mathur, 2009)

At short circuit current: $\mathrm{I}_{\mathrm{PV}}=\mathrm{I}_{\mathrm{sc} 0}, \mathrm{~V}_{\mathrm{PV}}=0$ (given in datasheet)

At open circuit voltage: $\mathrm{I}_{\mathrm{PV}}=0, \mathrm{~V}_{\mathrm{PV}}=\mathrm{V}_{\mathrm{oc} 0}$ (given in datasheet)

At the maximum power point: $\mathrm{I}_{\mathrm{PV}}=\mathrm{I}_{\mathrm{mp} 0}, \mathrm{~V}_{\mathrm{PV}}=\mathrm{V}_{\mathrm{mp} 0}$ (given in datasheet)

At the maximum power point: $\mathrm{dP} / \mathrm{d} \mathrm{V}_{\mathrm{mp}}=0$

At short circuit: $\mathrm{dI}_{\mathrm{sc}} / \mathrm{dV}=-1 / \mathrm{R}_{\text {shref }}$ (can be obtained from the characteristic curve given in datasheet)

Under reference conditions equation (1) can be rewritten as,

$$
\begin{gathered}
I_{P V}=I_{\text {phref }}-I_{\text {rref }}\left[\exp \left\{\frac{V_{P V}+I_{P V} R_{\text {seref }}}{V_{\text {tref }}}\right\}-1\right]-\frac{\left(V_{P V}+I_{P V} R_{\text {seref }}\right)}{R_{\text {shref }}} \\
I_{\text {sc } 0}=I_{\text {phref }}-I_{\text {rref }}\left[\exp \left\{\frac{I_{\text {sc } 0} R_{\text {seref }}}{V_{\text {tref }}}\right\}-1\right]-\frac{\left(I_{\text {sc0 }} R_{\text {seref }}\right)}{R_{\text {shref }}} \\
0=I_{\text {phref }}-I_{\text {rref }}\left[\exp \left\{\frac{V_{\text {oc } 0}}{V_{\text {tref }}}\right\}-1\right]-\frac{\left(V_{\text {oco } 0}\right)}{R_{\text {shref }}}
\end{gathered}
$$




$$
\begin{aligned}
& I_{s c 0}=I_{\text {phref }}-I_{\text {rref }}\left[\exp \left\{\frac{V_{m p 0}+I_{m p 0} R_{\text {seref }}}{V_{\text {tref }}}\right\}-1\right]-\frac{\left(V_{m p 0}+I_{m p 0} R_{\text {seref }}\right)}{R_{\text {shref }}} \\
& \frac{d\left(I_{P V} V_{P V}\right)}{d V}=0 \text {, under Maximum power point condition } \\
& \frac{d\left(I_{P V}\right)}{d V}=-\frac{1}{R_{\text {phref }}} \text {, at short circuit point }
\end{aligned}
$$

The five reference parameters ( $I_{\text {phref }}, I_{\text {rref }}, V_{\text {tref }}, R_{\text {seref }}$ and $R_{\text {shref }}$ ) can be obtained by simultaneously solving Equations (3) through (7). In the improved model, the effect of ideality factor, series and shunt resistance with respect to insolation and temperature has been added. From literature, the following relations can be obtained:

$$
\begin{aligned}
& I_{p h}=G \times I_{s c} \\
& I_{s c}=I_{\text {scref }}\left[1+\alpha\left(T-T_{\text {ref }}\right)\right] \text { and } I_{\text {scref }}=I_{\text {phref }} \\
& \quad I_{r}=I_{\text {rref }}\left(\frac{T}{T_{\text {ref }}}\right)^{\frac{3}{n}} \exp \left[b\left(\frac{1}{T_{\text {ref }}}-\frac{1}{T}\right)\right] \\
& V_{t}=V_{\text {tree }}\left[\frac{T}{T_{\text {ref }}}\right] \\
& G\left[\frac{V_{t}}{I_{r}} \exp \left(\frac{-\left\{V_{m p}+I_{m p} R_{s e}\right\}}{V_{t}}\right)+R_{s e}\right]=\left[\frac{V_{\text {tref }}}{I_{\text {reef }}} \exp \left(\frac{-\left\{V_{\text {mpref }}+I_{\text {mpref }} R_{\text {seref }}\right\}}{V_{\text {tref }}}\right)+R_{\text {ser }}\right] \\
& R_{\text {sh }}=R_{\text {shreef }}
\end{aligned}
$$

The above equations are used to simulate the model of existing solar panel (Solkar-Monocrstalline type) which consists of 36 cells in series. The simulation is carried out using Matlab software (Hiren Patel and Vivek Agarwal, 2008; www.Mathworks.com).

As with the connection of cells to form panels, a number of panels can be connected in series string to increase the voltage level, in parallel to increase the current level or in a combination of the two. The exact configuration depends on the current and voltage requirements of the load. Matching of the interconnected panels in respect of their outputs can maximize the efficiency of the array. The conventional PV panel is constructed of several PV cells (normally 36 cells) connected in series. In the PV power generation system, multiple PV panels are generally connected in series in order to obtain sufficient dc voltage. If there is one shaded panel in a series connected array, it can then act as a load to the array. It may cause damage to the panel due to the heavy current passing through it in the reverse direction. To prevent this damage, bypass diodes are connected in anti parallel with each panel, and, in case of the panel being shaded current flows through the bypass diode rather than through the panel. In series connected array, even the slightest shadow falling on a PV panel causes a significant drop in generation power. For this study, three panels connected in series have been considered. The same concept can be extended to a number of panels connected in series. Figure 2 shows that the series connection of three panels with bypass diode (Shimizu et.al, 2001).

Figure 3 shows the typical V-I and P-V characteristics of three series connected panels with same illumination. The maximum power is 110.9 watts. The maximum power produced by all the panels is equal as they are equally illuminated. When they are connected in series all the panels contribute power to the load. That is the maximum possible power produced by the PV array consisting of three panels each rated at the maximum power of 37.08 watts is 110.9 watts. When these three panels are not equally illuminated the power contributed by individual panels will be different and maximum power contributed by the array will be less than 110.9 watts.

Figure 4.a shows the characteristics of SPVA consisting of three series connected panels where each panel receives different illumination. Say Panel-1 receives 100\% illumination; Panel-2 receives 70\% illumination and Panel-3 receives $50 \%$ illumination. The operating point of each panel is given by the point of intersection operating lines $\mathrm{I}_{1}, \mathrm{I}_{2} \& \mathrm{I}_{3}$. As the load current increases from zero to short circuit current, the operating point of each panel moves as shown in Fig.4.a. i.e. $V_{11} \rightarrow V_{12} \rightarrow V_{13}$ for Panel-1, $V_{21} \rightarrow V_{22} \rightarrow V_{23}$ for Panel-2 and $V_{31} \rightarrow V_{32} \rightarrow V_{33}$ for Panel-3 respectively. The operating points $\mathrm{V}_{23}$ for Panel-2 and $\mathrm{V}_{32}$ and $\mathrm{V}_{33}$ for Panel -3 (both shaded panels) are lying on the negative $\mathrm{X}$ axis.

On the operation line $\mathrm{I}_{1}$ the $50 \%$ shaded panel, $\mathrm{PV}_{3}$, generates its maximum power, whereas the other two panels do not generate their maximum power yet. But all the three panels are contributing power. When the operation line moves to $\mathrm{I}_{2}$, the operation points of $\mathrm{PV}_{1}, \mathrm{PV}_{2}$ and $\mathrm{PV}_{3}$ move to $\mathrm{V}_{12}, \mathrm{~V}_{22}$ and $\mathrm{V}_{32}$ respectively. The generation power of $\mathrm{PV}_{1}$ and $\mathrm{PV}_{2}$ increases. The operation point $\mathrm{V}_{32}$ of Panel-3 moves to negative voltage region because the current generated by other 
two panels flow through the bypass diode connected in anti-parallel with Panel-3, and the resultant power generated by $\mathrm{PV}_{3}$ becomes negative. That is $\mathrm{PV}_{3}$ cannot generate any power and causes a power loss, $\mathrm{PV}_{3 \mathrm{Loss}}$. When the operating line moves to $I_{1}, P V_{1}$ generates its maximum power, but the operating points $V_{23}$ and $V_{33}$ move to negative voltage region consequently cause the power loss, $\mathrm{PV}_{23 \text { Loss. }}$. Hence the output power on the system is decreased to

$$
\mathrm{PV}_{\text {total }}=\mathrm{PV}_{\text {loutmax }}-\mathrm{PV}_{3 \text { Loss } 1}-\mathrm{PV}_{23 \text { Loss }}
$$

The generation power is following the relation $\mathrm{PV}_{\text {lout }}>\mathrm{PV}_{\text {2out }}>\mathrm{PV}_{3 \text { out }}$ in this case. The total $\mathrm{P}-\mathrm{V}$ characteristic of the series connected system is shown in Figure 4.b. Figures 4.a and 4.b show the electrical characteristics of SPVA with bypass diodes with $\mathrm{G}_{1}=100 \%, \mathrm{G}_{2}=70 \%$ and $\mathrm{G}_{3}=50 \%$. The results are consolidated in Table- 1 . Though the maximum power goes up to 58.2 watts, the bypass diodes introduce multiple peaks in the characteristics.

Figure 5.a and Figure 5.b show the V-P characteristics of SPVA for different shading with its maximum power point indicated. The shading patterns are selected randomly. The maximum power point algorithm is written in Matlab M-code to indicate the global peak point in the characteristics. The results are consolidated in Table.2

\section{Validation of the Model}

For this study Solkar panel 3712/0507-Monocrystalline type that consists of 36 cells in series is used. Ratings of the panels used in this experiment are $\mathrm{P}_{\max }=37.08 \mathrm{~W}, \mathrm{I}_{\mathrm{mp}}=2.25 \mathrm{~A}, \mathrm{~V}_{\mathrm{mp}}=16.56 \mathrm{~V}, \mathrm{~V}_{\mathrm{oc}}=21.24 \mathrm{~V}$ and $\mathrm{I}_{\mathrm{sc}}=2.55 \mathrm{~A}$ at an insolation level of $1000 \mathrm{~W} / \mathrm{m}^{2}$ and $25^{\circ} \mathrm{C}$. The shading effect is artificially generated by tilting the panels at different angles. The three series connected panels in SPVA are tilted such that they receive insolation levels of $\mathrm{G}_{1}=100 \%$, $\mathrm{G}_{2}=70 \% \& \mathrm{G}_{3}=50 \%$ respectively. The insolation level is measured with reference to short circuit current, that is for $\mathrm{G}=100 \%$, the reference short circuit current is 2.55 A. The Solar panel is tilted till the required insolation level is obtained by measuring the value of $\mathrm{I}_{\mathrm{sc}}$. Figure 6 shows the schematic of hardware arrangement for observing the practical characteristics. A linear MOSFET is used as a load resistance. Gate-Source port of the MOSFET is driven by a low frequency triangular wave generator. Voltage of the panel is given to the X-input of a CRO. Voltage proportional to load current is obtained as voltage drop across a small series connected resistance. The current signal is inverted and given as Y-input to the CRO. I-V characteristics of the SPV will be observed on the CRO screen. For good results, the gate signal should be large enough to cover the entire range of the resistance variation of the MOSFET without driving it deep in cut-off or saturation mode. The characteristic is traced on the screen once every cycle of the gate signal. A signal frequency of $1 \mathrm{~Hz}$ was used to minimize the transients due to gate-source capacitance. The hardware set up of electronic load is shown in Figure 7. The practical validation of the simulation model for the above said shading pattern using electronic load is shown in Figure 8.

\section{Conclusion}

In this paper the effect of non uniform illumination on a series connected solar PV cells is discussed in detail using Matlab software. In a series connected SPVA non-uniform insolation can damage poorly illuminated cells. A large proportion of electrical power generated by highly illuminated cells is wasted as heat in poorly illuminated cells. It is observed from the above discussions, the use of bypass diodes can save the poorly illuminated panels from damage and also make this energy available to the load. But the P-V characteristics under non uniform insolation with bypass diodes contain multiple peaks. The magnitude of the global maxima is dependent on the array configuration and shading patterns. It is demonstrated that, if the likely shading pattern on the PV array is known, the simulation model is handy to design the most optimum configuration of the PV array to extract the maximum power. As the developed model in this paper is based on the equations that take care about the model parameter variations with respect to environmental conditions, it can be used readily to predetermine the behavior of any SPV array having different number of cells in series and parallel, different number of bypass diodes and shadow conditions.

\section{Acknowledgement}

The authors are thankful to the management of SSN college of Engineering, Chennai for providing all the experimental and computational facilities to carryout this work.

\section{References}

Eftichios Koutroulis, Kostas Kalkaitzakis, and Nicholas C. Voulgaris. (2001). Development of a Microcontroller-based Photovoltaic maximum power point tracking control system, IEEE Transactions on Power Electronics, vol. 16, No.1

Gow.J.A. and Manning.C.D. (1996). Development of a Model for Photovoltaic Arrays Suitable for use in Simulation Studies of Solar Energy Conversion systems, Power Electronics and Variable Speed Drives, Conference Publication No. 429, pp-69-74.

G.Walker. (2001). Evaluating MPPT converter topologies using a MATLAB PV model, Journal of Electrical and Electronics Engineering, vol. 21, no. 1, pp. 49-56. 
Hiren Patel and Vivek Agarwal. (2008). MATLAB-Based Modeling to Study the Effects of Partial Shading on PV Array Characteristics , IEEE Transactions on Energy Conversion, vol. 23, no. 1, pp 302-310

H. Kawamura, K. Naka, N. Yonekura, S. Yamanaka, H. Ohno, and K. Naito. (2003). Simulation of I-V characteristics of a PV module with shaded PV cells, Solar Energy Mater. Solar Cells, vol. 75, no. 3/4, pp. 613-621.

Karatepe, E., Boztepe, M. and Colak, M. (2006). Neural network based solar cell model, Energy Conversion and Management: 47, pp 1159- 1178.

K. H .Hussein, Muta. I, Hoshino. T, Osakada. M. (1995).Maximum photovoltaic power tracking: an algorithm for rapidly changing atmospheric conditions, IEE Proceedings on Generation, Transmission and Distribution, Vol. 142(1), pp. $59-64$.

M. C. Alonso-Gracia, J. M. Ruiz, and F. Chenlo. (2006). Experimental study of mismatch and shading effects in the I-V characteristic of a photovoltaic module, Solar Energy Materials and Solar Cells, vol. 90, no. 3, pp. $329-340$.

Ramaprabha.R. and B.L.Mathur. (2008). Modelling and Simulation of Solar PV array Under Partial Shaded conditions, Proceedings of IEEE International Conference on Sustainable Energy Technologies, pp. 12 -16, Singapore

Ramaprabha.R. B.L.Mathur and M.Sharanya. (2009). Solar Array Modelling and Simulation MPPT using Neural Network, Proceedings of International Conference on Control, Automation, Communication and Energy Conservation, pp. $12-16$, Erode, Tamilnadu.

S. Jain and V.Agarwal. (2004).A new algorithm for rapid tracking of approximate maximum power point in photovoltaics systems, IEEE Power Electronics Letters, vol. 2, no. 1, pp. 16-19.

T. Shimizu, M. Hirakata, T. Kamezawa, and H. Watanabe. (2001).Generation control circuit for photovoltaic modules, IEEE Transactions on Power Electronics, vol. 16, no. 3, pp. 293-300.

Yingying Kuai and S. Yuvarajan. (2006). An electronic load for testing photovoltaic panels, Journal of Power Sources, Elsevier, pp 308-313.

http://www.Mathworks.com

Table 1. Consolidated Results for a Particular Shading Pattern

\begin{tabular}{|l|c|}
\hline Maximum Power of Panel-1 with $\mathrm{G}_{1}, \mathrm{P}_{\max 1}$ & $37.02 \mathrm{~W}$ \\
\hline Maximum Power of Panel-2 with $\mathrm{G}_{2}, \mathrm{P}_{\max 2}$ & $23.89 \mathrm{~W}$ \\
\hline Maximum Power of Panel-3 with $\mathrm{G}_{3}, \mathrm{P}_{\max 3}$ & $15.61 \mathrm{~W}$ \\
\hline Total Power expected to be produced by series connection, $\mathrm{P}_{\operatorname{maxtota}}=\left(\mathrm{P}_{\max 1}+\mathrm{P}_{\max 2}+\mathrm{P}_{\max 3}\right)$ & $76.52 \mathrm{~W}$ \\
\hline Total power produced by series connected panels without bypass diode & $46.45 \mathrm{~W}$ \\
\hline Total power produced by series connected panels with bypass diode & $58.24 \mathrm{~W}$ \\
\hline
\end{tabular}

Table 2. Ouput Power for Different Shading Patterns

\begin{tabular}{|c|c|c|c|c|}
\hline Shading Pattern & G1 & G2 & G3 & Global Maximum Power (Watts) \\
\hline SP-1 & 77 & 79 & 19 & 54.46 \\
\hline SP-2 & 49 & 45 & 64 & 45.22 \\
\hline SP-3 & 69 & 32 & 95 & 52.09 \\
\hline SP-4 & 3 & 44 & 38 & 23.34 \\
\hline SP-5 & 71 & 3 & 28 & 24.14 \\
\hline SP-6 & 5 & 9 & 83 & 29.14 \\
\hline SP-7 & 82 & 82 & 72 & 80.49 \\
\hline SP-8 & 97 & 65 & 80 & 74.51 \\
\hline SP-9 & 45 & 43 & 83 & 43.7 \\
\hline SP-10 & 15 & 66 & 52 & 35.77 \\
\hline SP-11 & 6 & 68 & 4 & 23.13 \\
\hline SP-12 & 7 & 52 & 9 & 16.49 \\
\hline
\end{tabular}




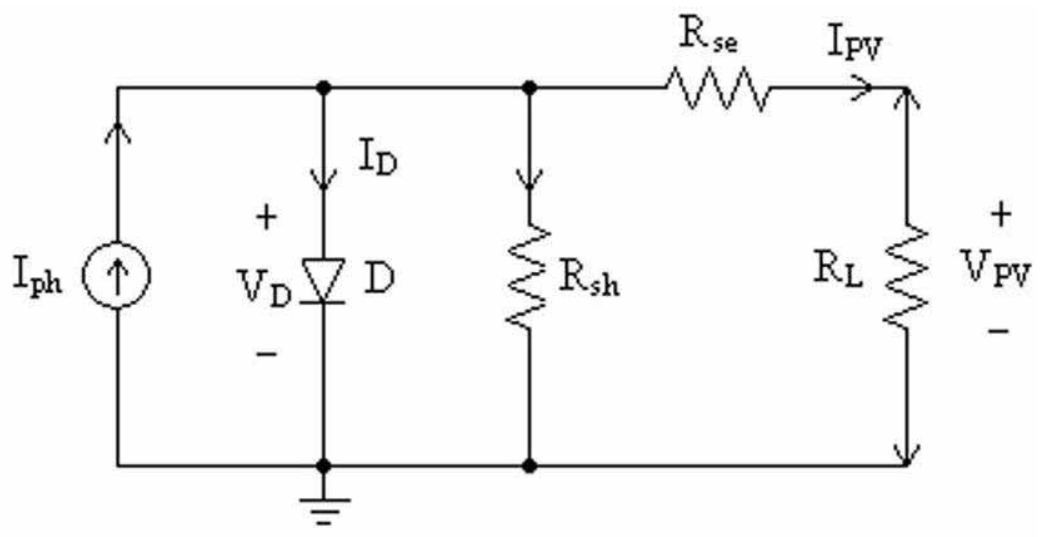

Figure 1. One diode model of Single PV Cell

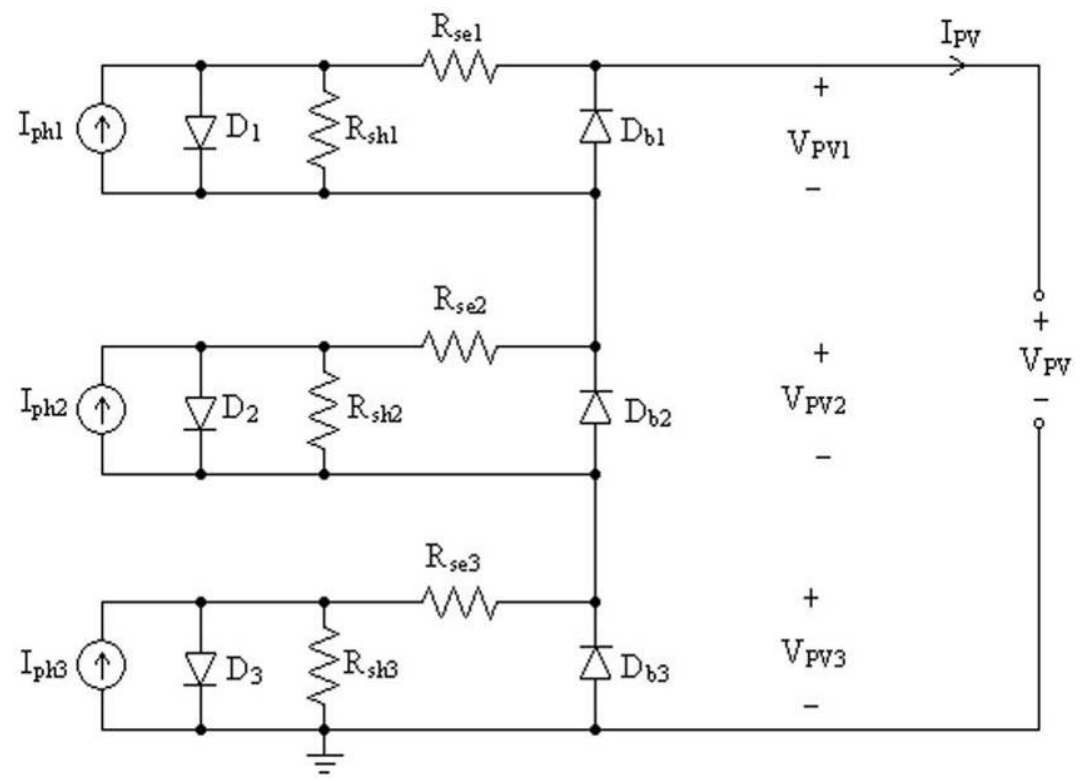

Figure 2. Series Connected SPVA with bypass diodes
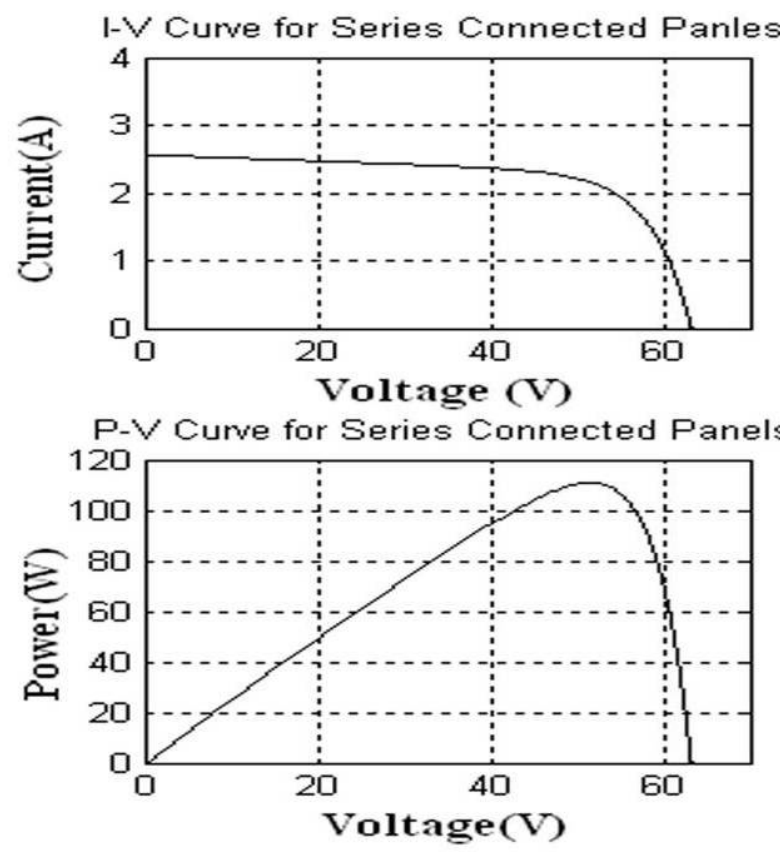

Figure 3. Characteristics of Series connected SPVA with uniform illumination 


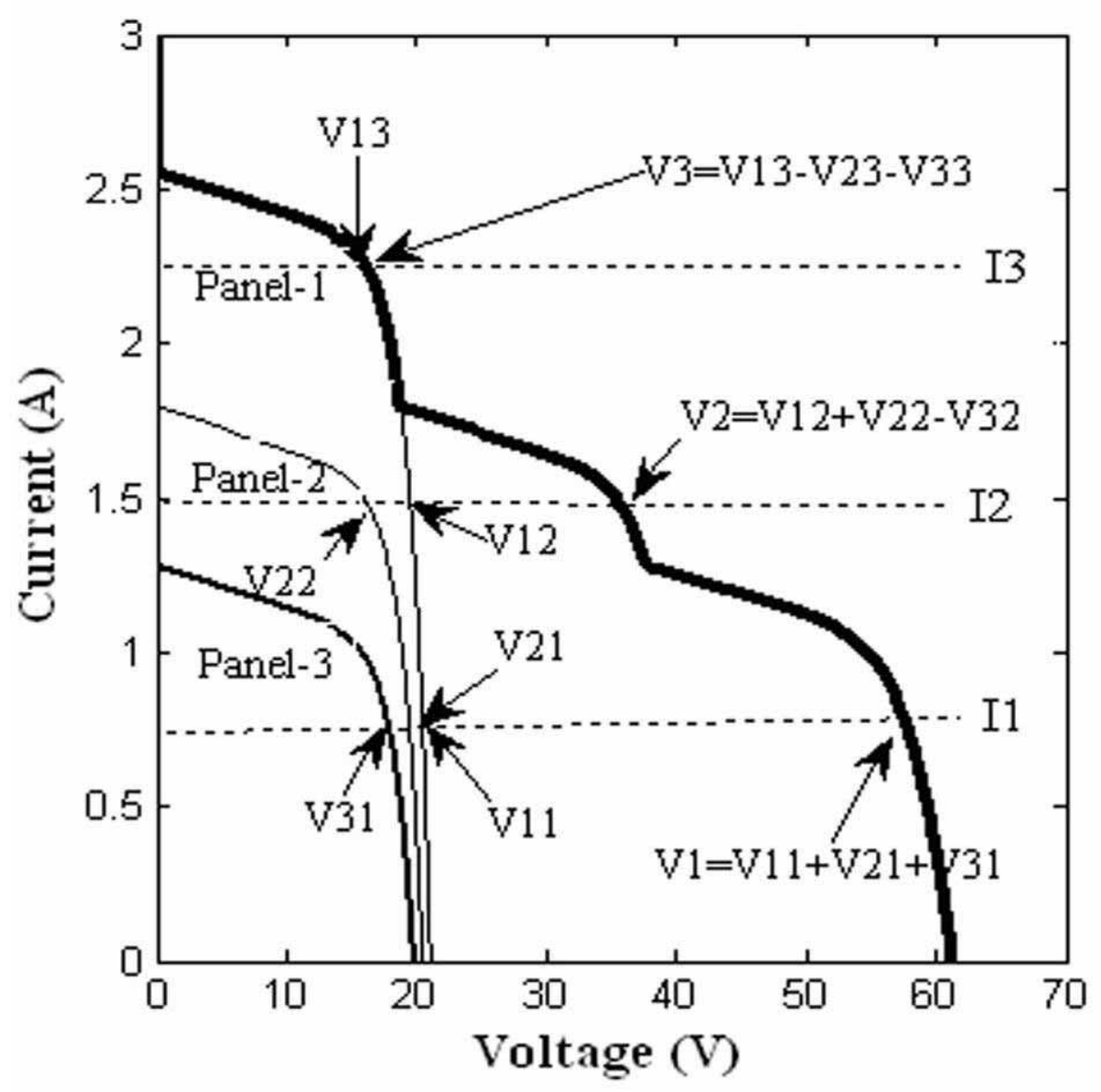

Figure 4. a. I-V characteristics of three series connected panels under partial shading

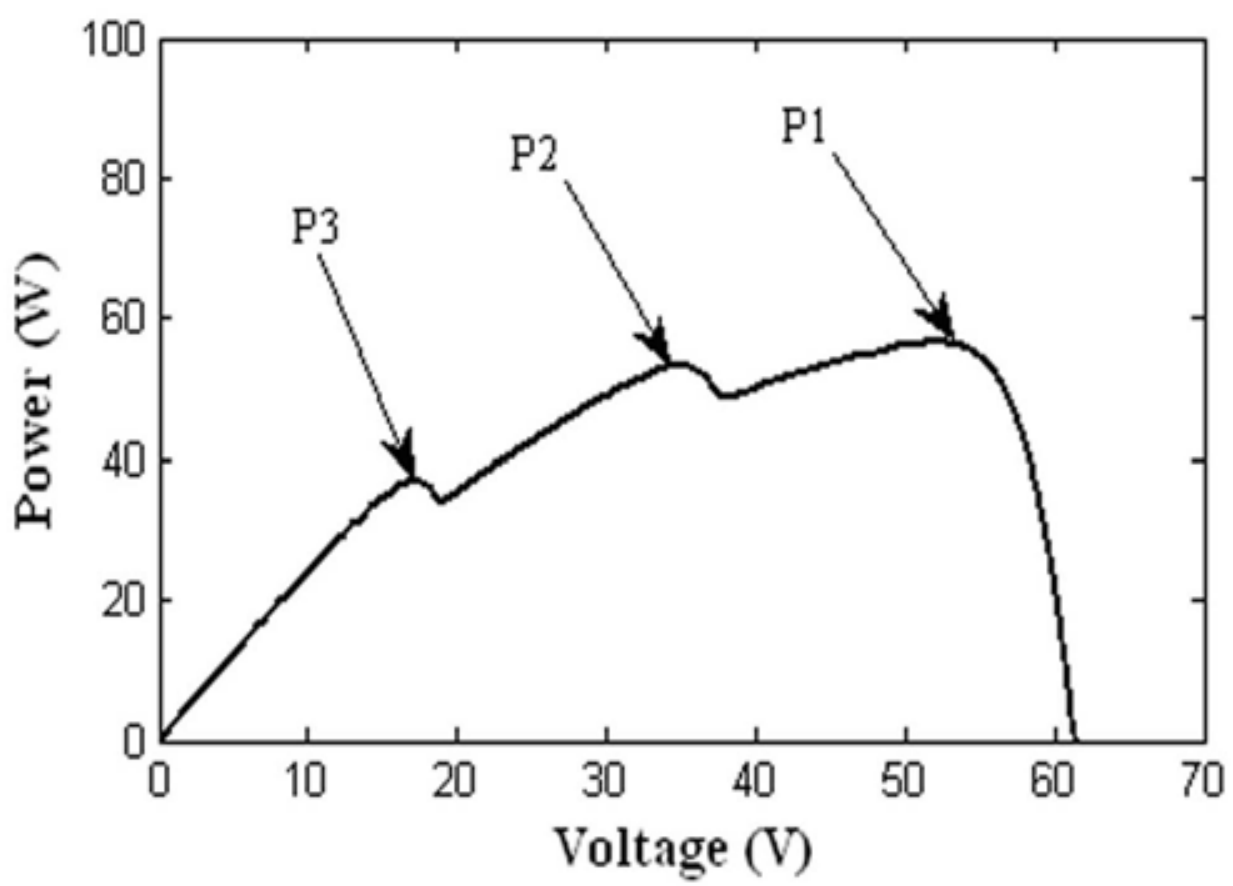

Figure 4. b. P-V characteristics of three series connected panels under partial shading 


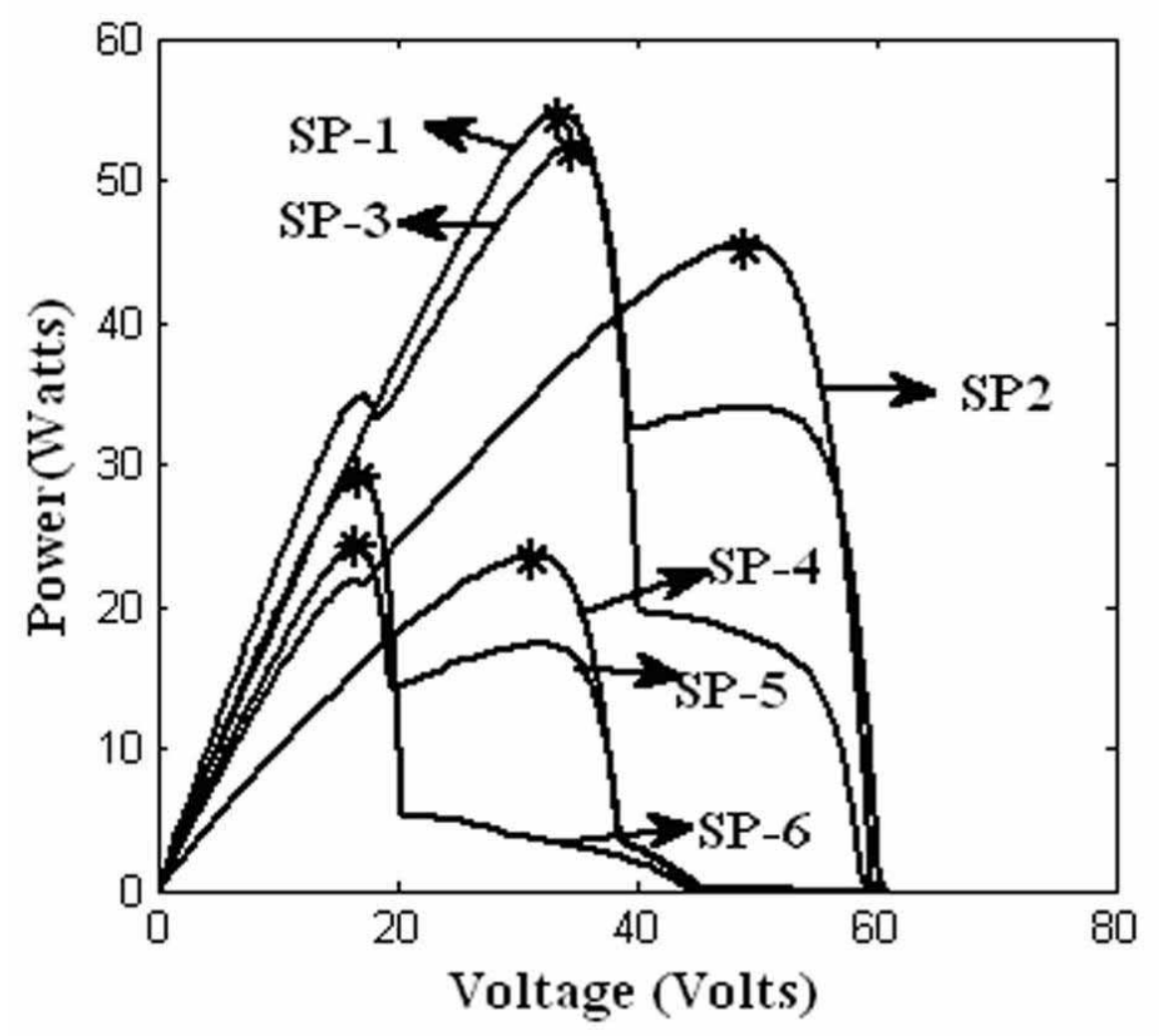

Figure 5. a. V-P curves for five different shading patterns

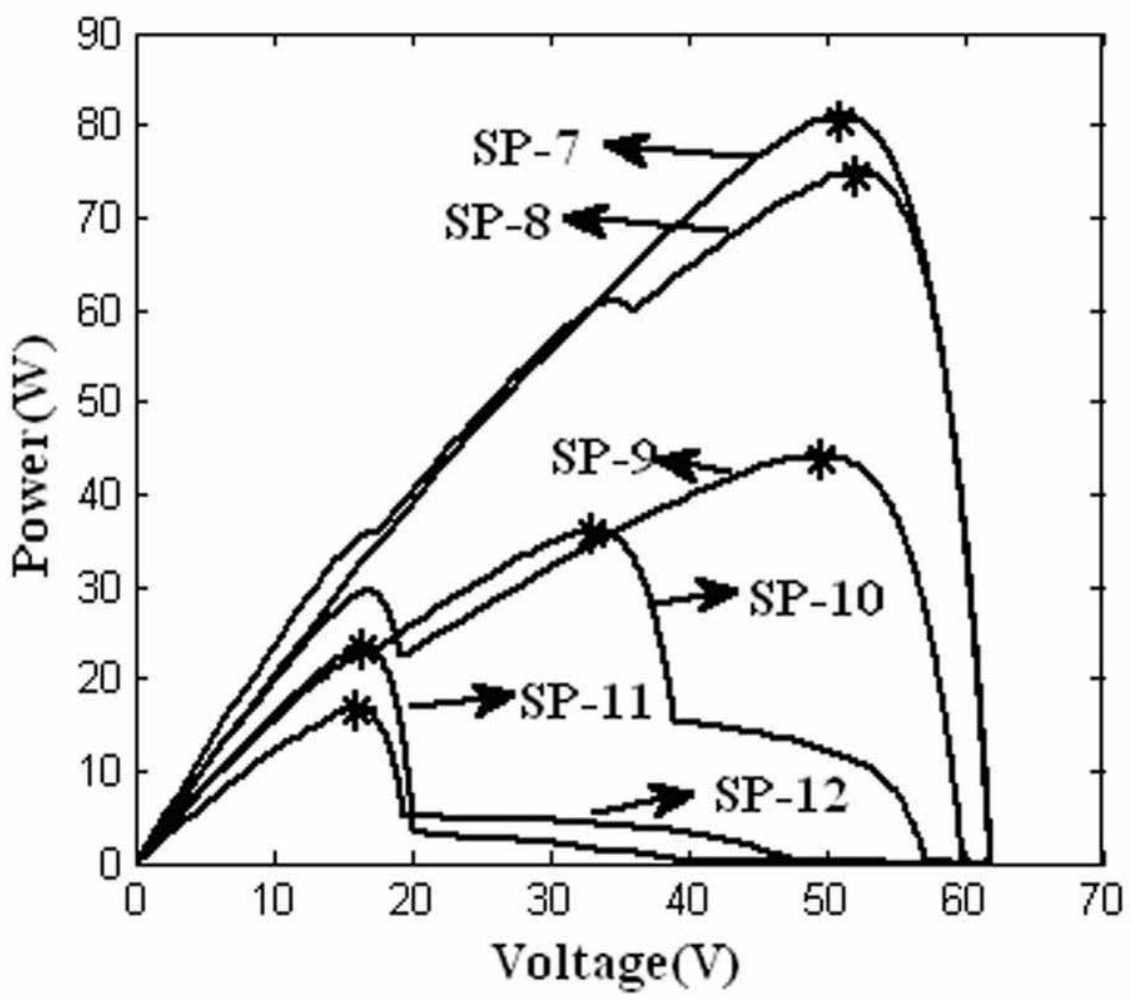

Figure 5. b. V-P curves for other five different shading patterns 


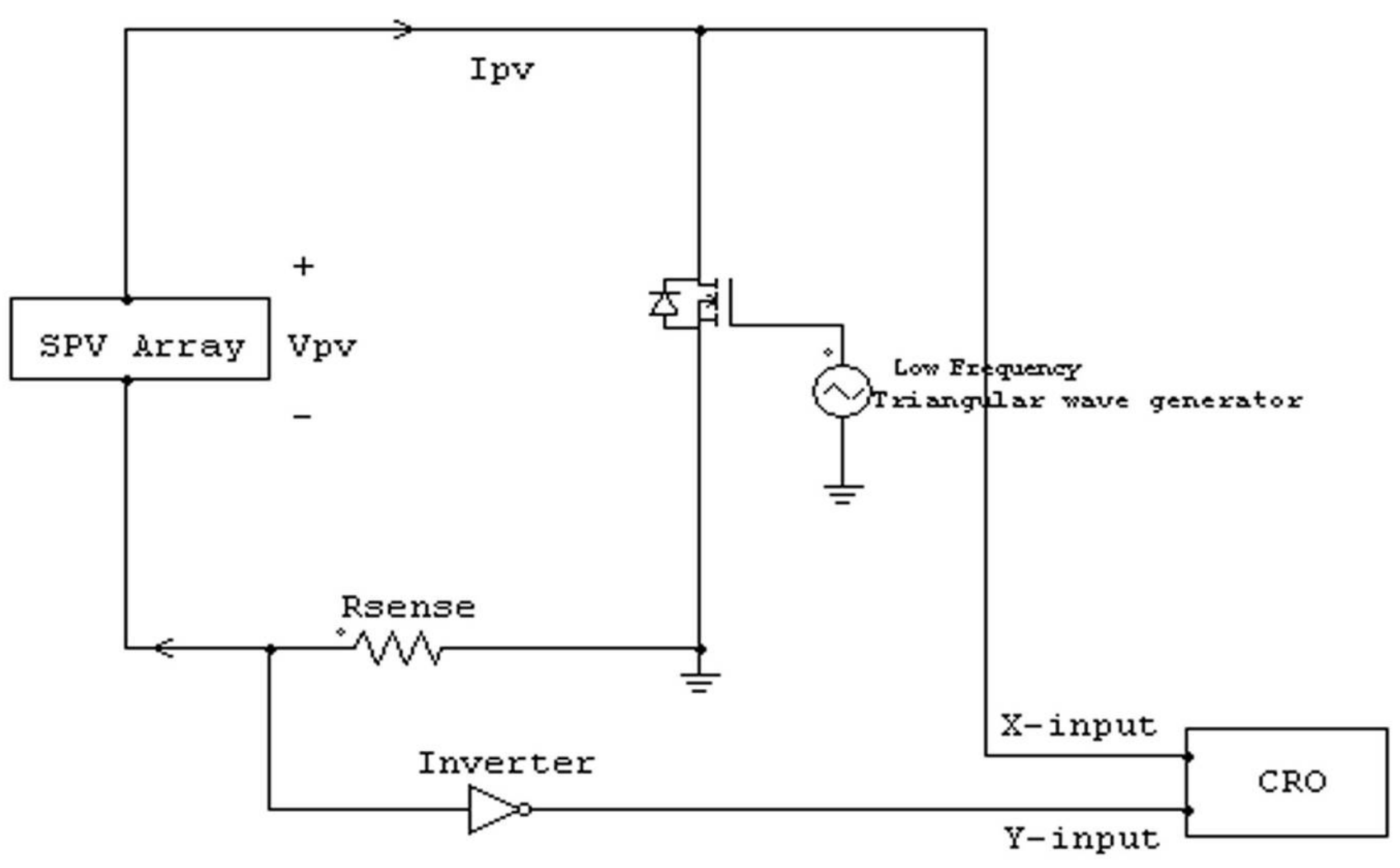

Figure 6. Block diagram for obtaining practical characteristics of SPV array

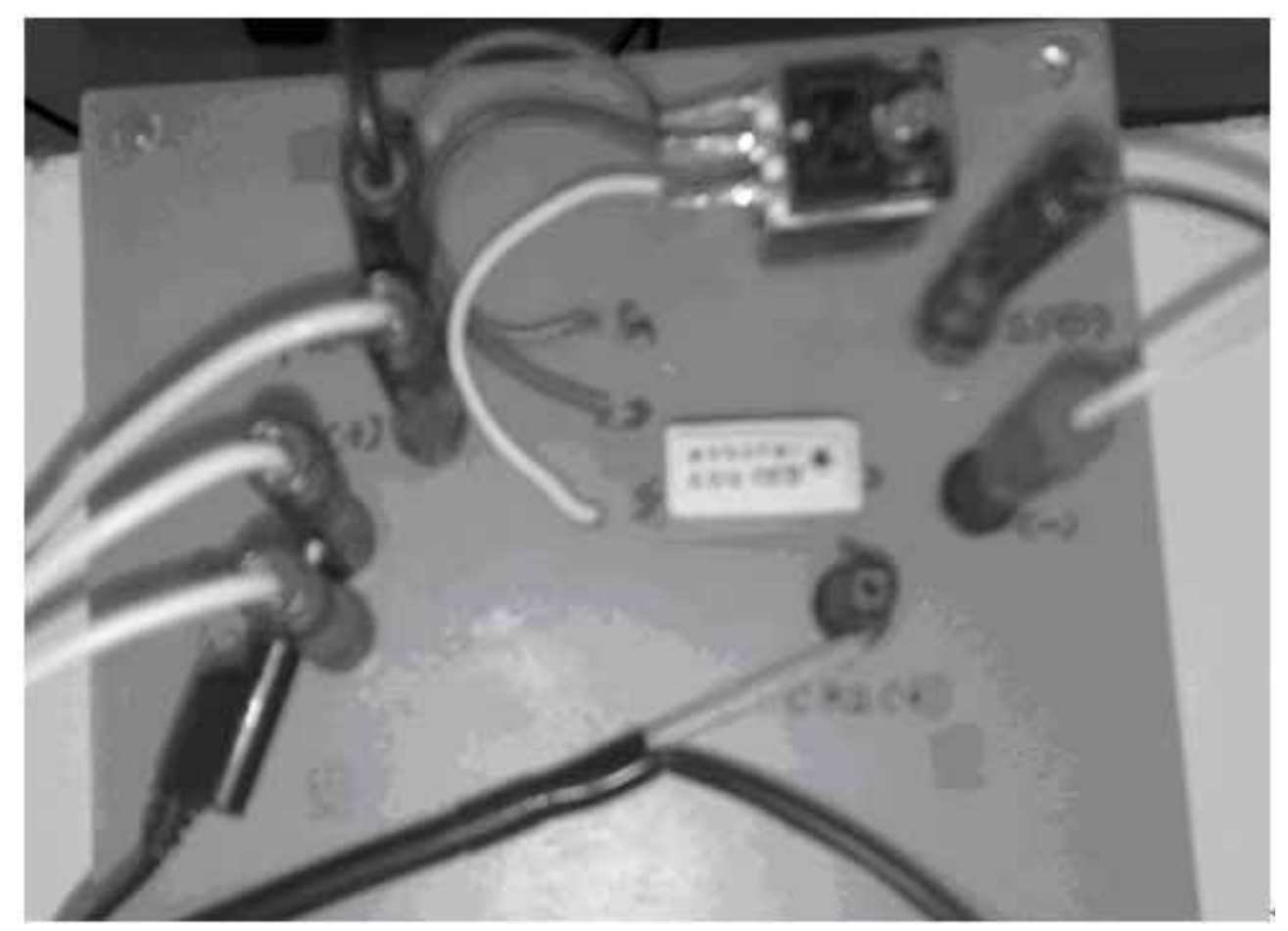

Figure 7. Hard ware set up of an Electronic Load 


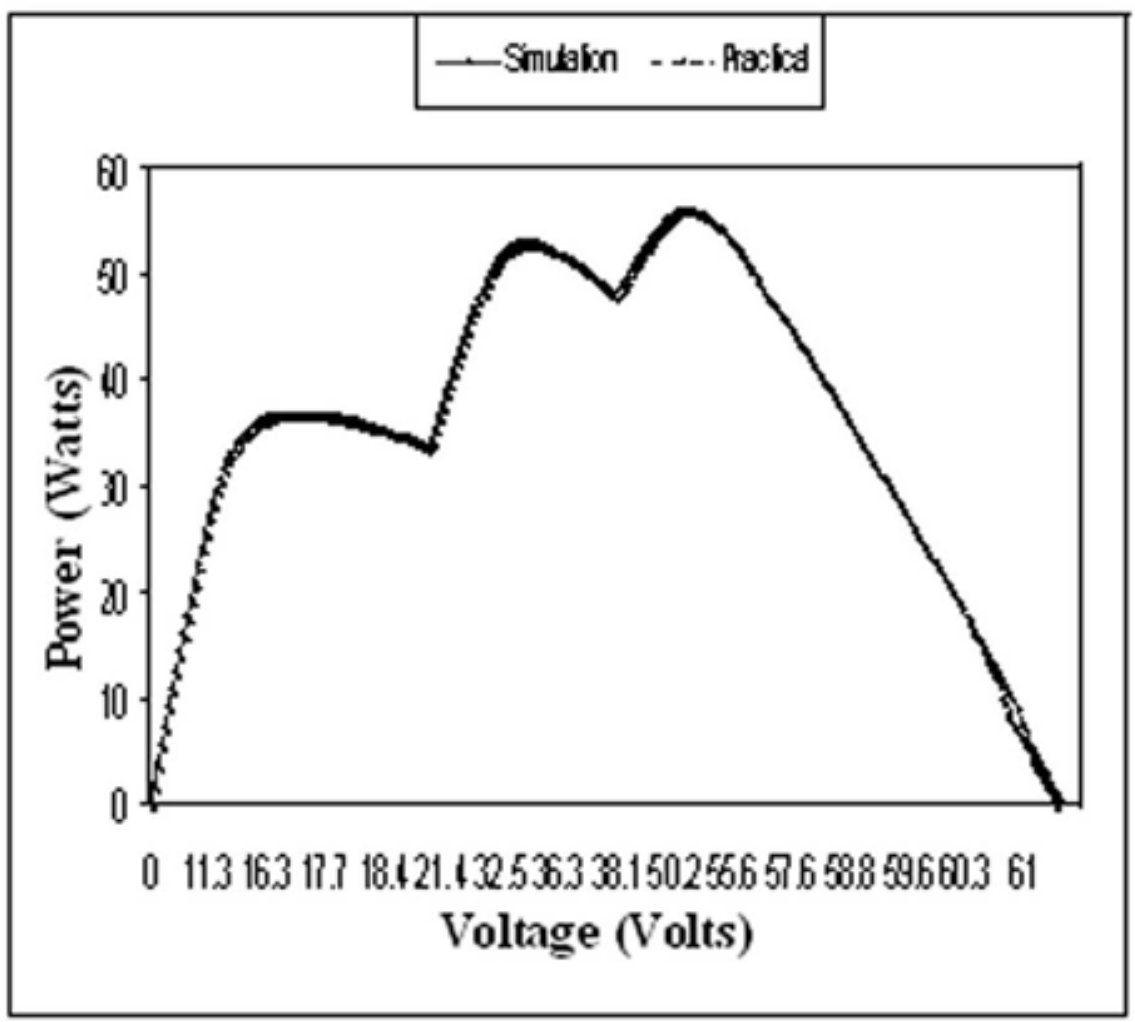

Figure 8. P-V characteristics of SPV array under partial shaded condition with bypass diodes-Validation of the model 